\title{
The Role of Pathogenesis-Related Proteins in the Tomato-Rhizoctonia solani Interaction
}

\author{
Parissa Taheri and Saeed Tarighi \\ Department of Crop Protection, Faculty of Agriculture, Ferdowsi University of Mashhad, P.O. Box 1163, Mashhad 9177948978, Iran \\ Correspondence should be addressed to Parissa Taheri, p-taheri@um.ac.ir
}

Received 19 September 2011; Accepted 19 December 2011

Academic Editor: Olivier Honnay

Copyright ( 2012 P. Taheri and S. Tarighi. This is an open access article distributed under the Creative Commons Attribution License, which permits unrestricted use, distribution, and reproduction in any medium, provided the original work is properly cited.

\begin{abstract}
Rhizoctonia solani is one of the most destructive pathogens causing foot rot disease on tomato. In this study, the molecular and cellular changes of a partially resistant (Sunny 6066) and a susceptible (Rio Grande) tomato cultivar after infection with necrotrophic soil-borne fungus $R$. solani were compared. The expression of defense-related genes such as chitinase (LOC544149) and peroxidase $(C E V I-1)$ in infected tomato cultivars was investigated using semiquantitative reverse transcription-polymerase chain reaction (RT-PCR). This method revealed elevated levels of expression for both genes in the partially resistant cultivar compared to the susceptible cultivar. One of the most prominent facets of basal plant defense responses is the formation of physical barriers at sites of attempted fungal penetration. These structures are produced around the sites of potential pathogen ingress to prevent pathogen progress in plant tissues. We investigated formation of lignin, as one of the most important structural barriers affecting plant resistance, using thioglycolic acid assay. A correlation was found between lignification and higher level of resistance in Sunny 6066 compared to Rio Grande cultivar. These findings suggest the involvement of chitinase, peroxidase, and lignin formation in defense responses of tomato plants against $R$. solani as a destructive pathogen.
\end{abstract}

\section{Introduction}

Tomato (Lycopersicon esculentum) is one of the most important vegetables in the world which suffers from various fungal diseases $[1,2]$. Foot rot disease of tomato plants was found in various greenhouses in Iran. Symptoms were characterized by soft rot of the seedling near the soil line. Rhizoctonia solani was consistently isolated from the damaged plant tissues. Rhizoctonia solani is a species complex composed of several anastomosis groups (AGs). This pathogen can survive in soil within diseased plant material as mycelia or sclerotia during unfavorable environmental conditions for several years. The pathogen is transported in infested soil or through movement of diseased plant tissues. Potential for seed borne inoculum also exists. In nature, usually $R$. solani has asexual reproduction and exists primarily as vegetative mycelium and/or sclerotia. The teleomorph of R. solani, Thanatephorus cucumeris, is classified in the phylum Basidiomycota. Formation of basidiospores on diseased host plants in nature is rarely observed. In favorable environmental conditions, following infection of the host plant by $R$. solani, sexual spores are formed on specialized structures called basidia. Four spores are produced on each basidium. Basidia are formed when enough moisture is available and sufficient growth of the fungus has occurred. Basidiospores are winddispersed and germinate in high moisture. Each basidiospore has a single nucleus. The hyphae produced by germinating spores will fuse or anastamose with each other to form new hyphae with a mixture of different types of nuclei [3].

To date, $R$. solani is divided into 14 AGs designated as AG 1 through 13 and bridging isolate (BI) group [4, 5]. Isolates belonging to AG BI have the ability to anastomose not only with isolates of AG BI, but also with other AGs of R. solani such as AG 2, AG 3, AG 6, and AG $8[6,7]$. Several AGs are further subdivided into intraspecific groups (ISGs) based on cultural morphology, nutritional requirements, temperature effect on growth, host specificity, frequency of hyphal anastomosis, and pathogenicity [7]. Isolates of AGs $1,2,3$, and 4 have been shown to be pathogenic on tomato $[8,9]$ and cause high yield losses every year worldwide. 
The growing concern about negative environmental effects of fungicides and appearance of fungicide-resistant pathogen strains is a motivating research for alternative protection methods. Among such novel strategies, understanding basal defense mechanisms to plan effective disease control methods has emerged as potential supplement in crop protection measures. One of the most important and effective plant defense mechanisms against various pathogens is activation of defense-related genes which are encoding defense proteins known as pathogenesis-related (PR) proteins. On the basis of amino acid sequence data and biochemical functions, PR proteins have been classified into 17 families so far [10].

The PR-3 and -4 families are comprised of chitinases. They hydrolyze the $\beta-1,4$ linkages between $\mathrm{N}$-acetylglucosamine residues of chitin, a structural polysaccharide of the cell wall of many fungi, such as $R$. solani. The enzyme is linked with the thinning of the growing hyphal tips of fungi, followed by a balloon-like swelling that eventually leads to a bursting of hyphae. Furthermore, the degradation products of the fungal cell wall, especially the oligomers, could serve as resistance elicitors [8]. A combination of chitinase and -1,3glucanase is known to be more effective than each enzyme alone against many fungi $[7,10]$. Application of an antiserum against a tomato chitinase as a probe to study the subcellular localization of this enzyme in the roots infected with Fusarium oxysporum f. sp. radicis-lycopersici revealed that chitinase accumulated earlier in the incompatible interaction than in the compatible one. However, in both systems, chitinase deposition was largely correlated with pathogen distribution [11]. The enzyme was found to accumulate in areas where host walls were in close contact with fungal cells. In contrast, the enzyme could not be detected in vacuoles and intracellular spaces. The substantial amount of chitinase found at the fungus cell surface supports the view of an antifungal activity. However, the preferential association of the enzyme with altered fungal wall areas indicates that chitinase activity is either preceded by the hydrolytic action of other enzymes such as $\beta$-1,3-glucanases or coincides with these enzymes [11]. More rapidly, induction of various classes of chitinases is also reported during an incompatible Cladosporium fulvum-tomato interaction than during a compatible interaction [12]. In the C. fulvumtomato pathosystem, resistance against the fungus correlates with early induction of transcription of genes encoding apoplastic chitinase and 1,3-b-glucanase and accumulation of these proteins in inoculated tomato leaves. For vacuolar, basic isoforms of chitinase and 1,3-b-glucanase, however, early gene transcript accumulation was observed in both incompatible and compatible interactions. Upregulation of the chitinase gene was observed most abundantly in resistant tomato genotypes which correlates well with the differences in gene expression observed in time course studies of compatible and incompatible C. ful.um-tomato interactions [13].

The PR-9 or peroxidases are key enzymes in the cell wallbuilding process, and it has been suggested that extracellular or wall-bound peroxidases would enhance resistance in various plant species against phytopathogens by the construction of a cell wall barrier that may hamper pathogen ingress and spread in plant cells. The PR-9 group contains a specific type of peroxidase that could act in cell wall reinforcement by catalyzing lignification [14] and enhance resistance against multiple pathogens with different life styles. It has been suggested that peroxidases are involved in the resistance of heated tomato fruits to infection with Botrytis cinerea as a destructive necrotrophic phytopathogen [15]. During the heat treatment, peroxidase activity was higher than in tomato fruits held at $20^{\circ} \mathrm{C}$, and new peroxidase isoforms appeared. These isoforms disappeared when the tomato fruits were removed to $20^{\circ} \mathrm{C}$ and the fruits became sensitive to fungal infection. These findings indicate the role of peroxidases in defense responses of tomato fruit against $B$. cinerea and high temperature stress may help in defense against the fungal infection [15].

Basal resistance should be a key component of a disease management strategy for $R$. solani on tomato. Regrettably, only a few moderately resistant tomato cultivars are available with commercially acceptable horticultural traits. More sources of resistance from commercial cultivars or wild species need to be identified. Breeders use wild Solanum spp. as sources of genes controlling traits of economic importance such as fruit characteristics, nutritional content, and general disease resistance [16]. Identifying sources of resistant tomato germplasm and the mechanisms involved in basal resistance to the pathogen would aid in the development of cultivars suitable for production in $R$. solani-infested fields.

Foot rot disease of tomato caused by $R$. solani has not been investigated at cellular and molecular levels yet. Therefore, the objective of this study was to examine basal defense and the cytomolecular aspects of tomato- $R$. solani interaction by chitinase and peroxidase gene expression and determining levels of lignin in the plant cells.

\section{Materials and Methods}

2.1. Plant Material and Growth Conditions. The tomato cultivars Sunny 6066 and Rio Grande, which are partially resistant and susceptible to $R$. Solani, respectively [17], were used in this study. Tomato seedlings grown in $10 \mathrm{~cm}$-diameter plastic pots for 6 weeks were used. The pots were filled with a commercial potting soil (Klassmann-Deilmann, Germany) and the plants were grown in greenhouse $\left(30 \pm 4^{\circ} \mathrm{C}\right.$; $16 / 8 \mathrm{~h}$ light/dark photoperiod). Six-week-old plants were used for inoculations.

\subsection{Pathogen Inoculation, Disease Evaluation, and Microscopic Analysis. Rhizoctonia solani isolate M-2.3 belonging to AG 4 HG I, obtained from symptomatic tomato in the Khorasan- Razavi province of Iran, was maintained on potato dextrose agar (PDA). In pathogenicity tests on the stem near the soil line, plants were transplanted into $15 \mathrm{~cm}$ diameter plastic pots and soil-inoculum mixture filled $2 \mathrm{~cm}$ above the original ground level, which contained $10 \mathrm{~g}$ of wheat bran inoculum incubated at $25^{\circ} \mathrm{C}$ for 3 weeks. Sterilized wheat bran served as the control. Disease evaluation was done 14 days post inoculation (dpi) by measuring the lesion length. Symptoms were observed, and the pathogen was reisolated}


as described by Misawa and Kuninaga [8]. Six replicate plants were inoculated in a completely randomized design and the experiment was repeated twice. Data were analyzed using the Mann-Whitney comparison test at $P=0.05$. Microscopic analysis of infected leaves was carried out by staining of fungal hyphae with aniline blue [18].

2.3. Thioglycolic Acid Assay. Lignin was quantified using thioglycoli acid (TGA) assay in which the lignin was bound to TGA to form lignin thioglycolic acid (LTGA) derivatives which can easily be extracted from tissue using sodium hydroxide and measured spectrophotometrically [19]. Each sample, consisting of $0.5 \mathrm{~g}$ of fresh plant tissue collected at different time points before and after inoculation, was ground in liquid nitrogen. LTGA derivatives were purified as described by Campbell and Ellis [20]. The purified LTGA derivatives were dissolved in $1 \mathrm{M} \mathrm{NaOH}$, and the absorbance of the samples at $280 \mathrm{~nm}$ was recorded using a UVIKON922 spectrophotometer (Kontron, B. R. S., Anderlecht, Belgium).

\subsection{RNA Extraction and Semiquantitative Reverse Transcrip-} tion-Polymerase Chain Reaction (RT-PCR). Total RNA was prepared from tomato leaves by TRIzol reagent (Invitrogen). After treatment with RNase-free DNase (TURBO DNAfree kit, Ambion, USA) to remove contaminating DNA, the RNA was quantified spectrophotometrically. Their qualities were checked by ethidium bromide staining of agarose gels. Afterward, cDNA was synthesized with oligo (dT) 18 primer and SuperScript Reverse Transcriptase (Invitrogen) and used for PCR amplification. The gene-specific PCR primers used in this study were designed for the chitinase (LOC544149) and peroxidase (CEVI-1) genes of tomato using primer 3 program. Tomato actin gene (LOC100147713) was used as a constitutive control in all gene expression experiments. Primer sequences were checked by BLAST analysis against rice genome sequence in order to guarantee gene-specific amplifications by the primers. The reaction included an initial 5 min denaturation at $94^{\circ} \mathrm{C}$, followed by $25-35$ cycles of PCR $\left(94^{\circ} \mathrm{C}, 30 \mathrm{~s} ; 58^{\circ} \mathrm{C}, 30 \mathrm{~s}\right.$, and $\left.72^{\circ} \mathrm{C}, 1 \mathrm{~min}\right)$, and a final extension period at $72^{\circ} \mathrm{C}$ for $7 \mathrm{~min}$. Several tests were performed in order to determine the optimal amount of cDNA (RT samples) per reaction and the optimal number of cycles of amplifications within the exponential range. PCR products were sampled after 20, 25, 30, and 35 cycles and were separated on $1 \%$ agarose gels and stained with ethidium bromide to determine the linearity of the PCRs. In each RT-PCR experiment, the RNA samples treated with the DNase (-RT samples) were added to test for the presence of genomic DNA contamination in the samples. Each RTPCR was repeated twice to ensure about reproducibility of the obtained data.

\section{Results}

3.1. Correlation between Resistance and Lignification. Thioglycolic acid (TGA) extractable cell wall complexes which are commonly thought to be lignin [20] were measured in order to quantitatively investigate the effect of lignin formation in resistance of tomato cultivars to the pathogen.

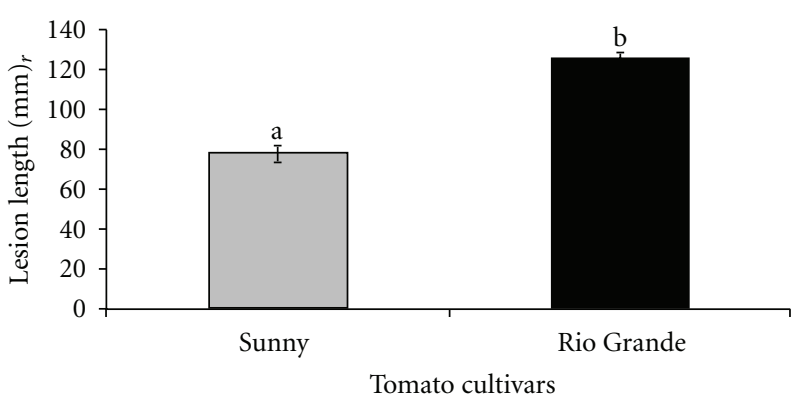

FIgure 1: Comparison of two different tomato cultivars in response to Rhizoctonia solani infection by measuring lesion length at 14 days after inoculation (dpi). Tomato plants (36 plants/cultivar, including 12 replicate plants/cultivar and 3 repetition/cultivar) were used in this experiment. Statistical data analysis was carried out using SPSS 12.0 for Windows. Different letters indicate significant differences between cultivars according to the Mann-Whitney comparison test $(P=0.05)$.

TGA assay revealed that the accumulation of lignin in Sunny cultivar at 24 hpi was significantly higher than in Rio Grande plants and reached to the highest level at $72 \mathrm{hpi}$ and then slightly decreased compared to Rio Grande cultivar. The level of lignin detected in partially resistant sunny plants (Figure 1) using TGA assay was significantly higher than that of susceptible Rio Grande plants at all time points after challenge inoculation with $R$. solani (Figure 2). The progress of fungal infection was investigated by microscopic analysis. After contact with the tomato plant surface, the mycelia grew and produced infection structures which directly penetrate into the plant tissues. Initiation of $R$. solani growth on the epidermis was detected at $1 \mathrm{dpi}$, followed by formation of infection structures and infrequent penetration at 2 to $3 \mathrm{dpi}$ (data not shown). Compared with disease development in the Sunny cultivar, the onset of disease in the Rio Grande leaves was stronger and faster which might be linked to lower level of lignin formation as a structural barrier in the Rio Grande plants.

3.2. Transcription Analyses. Time course studies of defenserelated gene expression were carried out for the inoculated tomato leaves (Figure 3 ) to determine the time point of upregulation for each gene investigated in this study. The expression level of peroxidase gene (CEVI-1) increased at 12 hpi and reached its maximum at 48 hpi in the Rio Grande plants. However, an increase in PO-C1 expression at $6 \mathrm{hpi}$ and peaking at $18 \mathrm{hpi}$ was observed in Sunny cultivar (Figure 3).

Both Sunny and Rio Grande plants showed the highest level of chitinase (LOC544149) expression at 24 hpi. However, higher level of LOC544149 expression was observed in Sunny compared to Rio Grande cultivar at 12 hpi (Figure 3), indicating priming the chitinase gene expression in the partially resistant cultivar.

\section{Discussion}

The involvement of peroxidase, chitinase, and lignin formation in basal resistance of tomato to $R$. solani was examined 


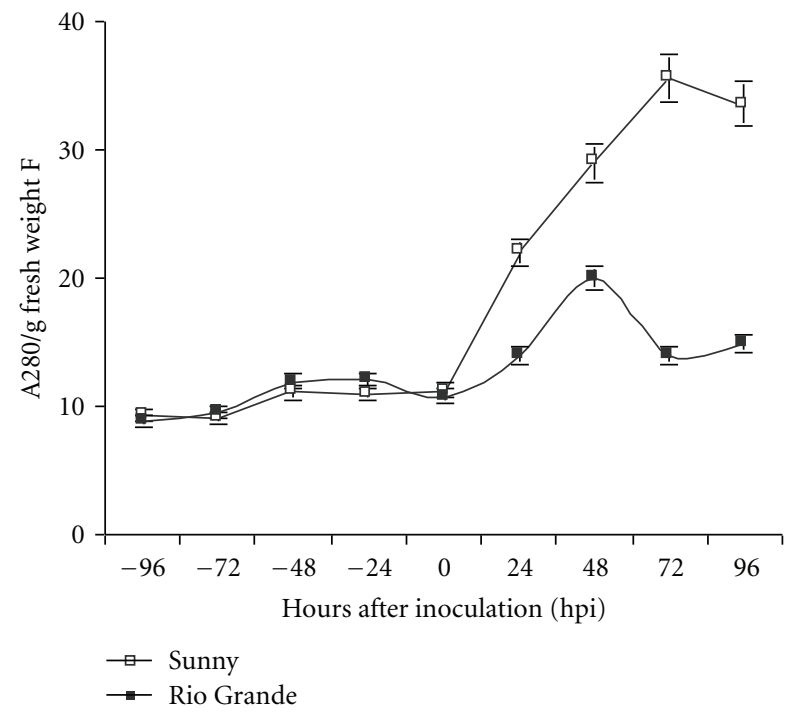

Figure 2: Lignin formation in the leaves of tomato cultivars at various time points before and after inoculation with Rhizoctonia solani. Data are means ( \pm standard error) of four replicates of a representative experiment. Each replicate consisted of one sample pooled from six individual plants. The experiment was repeated twice with similar results.

in the present study. We demonstrated that basal resistance to $R$. solani in Sunny cultivar was correlated with higher levels of lignin formation in this cultivar compared to Rio Grande as a susceptible tomato cultivar (Figures 1 and 2). These observations suggest that enhanced lignin formatin in the partially resistant Sunny plants may be a defense strategy against $R$. solani which is a destructive necrotrophic fungal pathogen on tomato and many other plant species. This is in agreement with our previous findings about defense mechanisms of rice, as a monocot model plant, against this phytopathogen [21]. Therefore, we can conclude that similar defense mechanisms are involved in resistance of monocot and dicot plants against $R$. solani.

Plants exhibit a variety of responses during infection by pathogens, insects, or abiotic stresses, many of which involve the activation of host defense genes. Activation of these genes leads to physical and biochemical changes in plant cells which are not favorable for damage progress in plant. Among the major biochemical changes is biosynthesis and the accumulation of inducible defense related proteins. Most of these proteins correspond to pathogenesis-related proteins. These proteins are mostly of low molecular weight, preferentially extracted at low $\mathrm{pH}$, resistant to proteolysis, and localized predominantly in the intercellular spaces of leaves.

The role of peroxidases, as a group of pathogenesis-related (PR) proteins which are involved in lignin production in phenylpropanoid pathway, in the interaction of tomato with some pathogens has been investigated. Peroxidases, grouped in PR9 family, have been associated with deposition of phenolics into plant cell walls during resistance responses [10]. Sareenal and associates [22] reported that enhancement

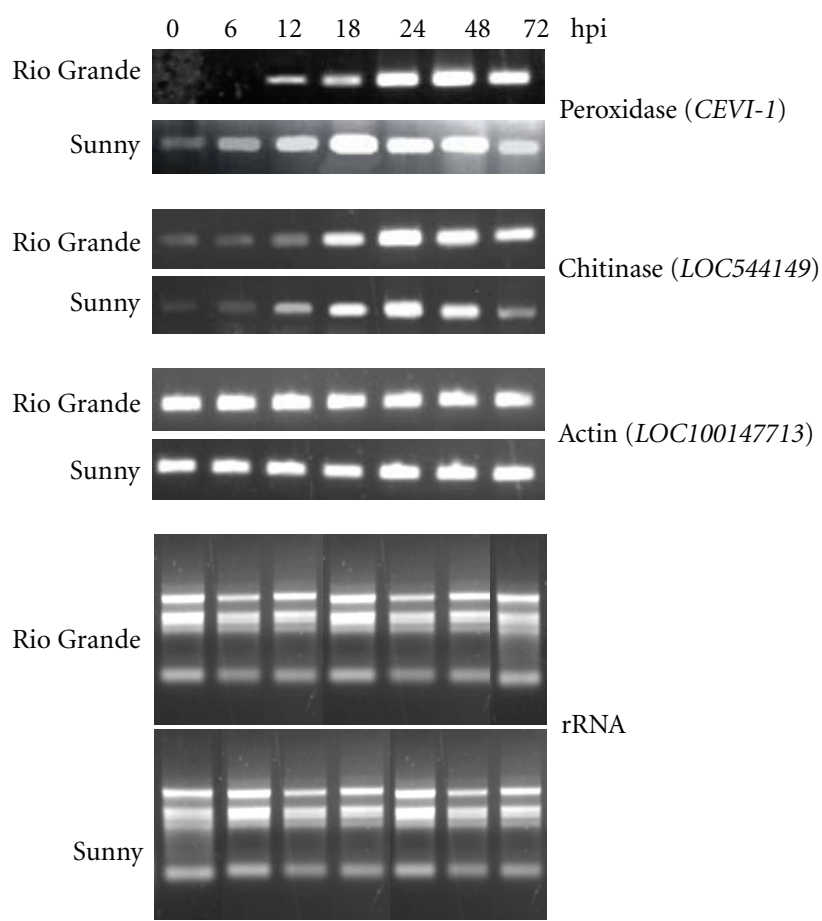

FIGURE 3: Expression patterns of the chitinase (LOC544149) and peroxidase (CEVI-1) genes in the leaf samples of tomato cultivars at different time points after inoculation with $R$. solani (hpi, hours after inoculation). Each time point represents eight leaves from eight different plants used for RNA extraction. Gene-specific primers for each of the defense genes were used in reverse transcription-polymerase chain reaction (RT-PCR). Control RTPCR reactions were carried out with specific primers for tomato actin gene. The experiment was repeated three times with similar results.

of the activity of peroxidase enzymes in response to the challenge inoculation with the pathogen under controlled conditions resulted in reduced symptom development and suppression of sheath blight disease in transgenic Pusa Basmatil (PB1) rice lines, which are engineered with rice chitinase gene (chi11) for resistance against the rice sheath blight pathogen, $R$. solani, compared to nontransgenic control plants, indicating the importance of the phenylpropanoid pathway and peroxidase in defense responses of rice plants against the pathogen. This is in accordance with our results demonstrating the role of peroxidase in resistance of Sunny cultivar to $R$. solani and its importance in defense mechanisms. A possible function of peroxidases is the formation of structural barriers such as cell wall enhancement and deposition of cell wall appositions, both of which can be involved in the polymerization of lignin or suberin, the crosslinking of wall glycoproteins or polysaccharides, and the dimerization of antimicrobial phenols. Lignin formation was investigated using phloroglucinol/ $\mathrm{HCl}$ test [23], and lignin was detected in Sunny plants at $24 \mathrm{hpi}$, which is downstream of peroxidase upregulation (Figure 3 ). This finding indicates that peroxidase might be involved in lignin deposition in partially resistant Sunny cultivar against $R$. solani. Therefore, one possible mechanism of basal resistance in Sunny plants 
can be linked to the defense pathways leading to formation of structural barriers such as lignin. In the transcript analyses, increased expression of the peroxidase gene (CEVI-1) was recorded in inoculated tomato plants. Together, these findings point to the importance of peroxidase-dependent phenolics production as a defense mechanism involved in basal resistance in our pathosystem. Several reports likewise suggest that priming of peroxidase transcripts or activities in various plants which contributes to phenolics-mediated resistance against necrotrophic phytopathogens $[10,24]$.

Chitinase gene could activate the expression of pathogenesis-related (PR) genes, subsequently enhancing transgenic plant resistance to necrotrophic pathogens $[25,26]$. In the present study, a correlation was observed between higher level of resistance in Sunny plants and earlier upregulation of the chitinase gene (LOC544149) in this cultivar at $12 \mathrm{hpi}$. Therefore, chitinase might be a defense gene involved in basal resistance of Sunny plants to the pathogen. This finding is in agreement with the observations of Sridevi et al. [26] on the role of chitinase in resistance of rice plants to $R$. solani. Similarly in tomato, investigations of Chen and associates [25] revealed the involvement of chitinase in defense of the plants against Botrytis cinerea as a destructive phytopathogen with necrotrophic lifestyle.

So far, no detailed analyses on the defense mechanisms and signaling pathways involved in resistance of tomato to $R$. solani had been conducted. Thus, our results contribute to the understanding of basal resistance in the important tomato- $R$. solani pathosystem. Disease management strategies rely on our knowledge concerning cellular and molecular aspects of the tomato- $R$. solani interaction, defense mechanisms and signal transduction pathways involved in resistance against the pathogen [14]. Therefore, our knowledge about defense responses involved in basal resistance of tomato could be useful in breeding programs leading to obtain cultivars with higher levels of resistance. Application of partially resistant cultivars may prevent Rhizoctonia disease epidemics and decrease yield losses caused by this destructive soil-borne phytopathogen.

\section{Acknowledgment}

The authors thank Ferdowsi University of Mashhad for the financial support of this research.

\section{References}

[1] A. Fakhro, D. R. Andrade-Linares, S. von Bargen et al., "Impact of Piriformospora indica on tomato growth and on interaction with fungal and viral pathogens," Mycorrhiza, vol. 20, no. 3, pp. 191-200, 2010.

[2] B. Pharand, O. Carisse, and N. Benhamou, "Cytological aspects of compost-mediated induced resistance against Fusarium crown and root rot in tomato," Phytopathology, vol. 92, no. 4, pp. 424-438, 2002.

[3] J. Webster and R. W. S. Weber, Inrtoduction to Fungi, Cambridge University Press, 3rd edition, 2007.

[4] D. E. Carling, "Grouping in Rhizoctonia solani by hyphal anastomosis," in Rhizoctonia Species: Taxonomy, Molecular Biology,
Ecology, Pathology and Disease Control, B. Sneh, S. Jabaji-Hare, S. Neate, and G. Dijst, Eds., pp. 37-47, Kluwer Academic, Dordrecht, The Netherlands, 1996.

[5] D. E. Carling, R. E. Baird, R. D. Gitaitis, K. A. Brainard, and S. Kuninaga, "Characterization of AG-13, a newly reported anastomosis group of Rhizoctonia solani," Phytopathology, vol. 92, no. 8, pp. 893-899, 2002.

[6] S. Kuninaga, R. Yokosawa, and A. Ogoshi, "Some properties of anastomosis group 6 and BI in Rhizoctonia solani Kuhn," Annals of the Phytopathological Society of Japan, vol. 45, no. 2, pp. 207-214, 1979.

[7] B. Sneh, L. Burpee, and A. Ogoshi, Identification of Rhizoctonia Species, The American Phytopathological Society Press, St. Paul, Minn, USA, 1991.

[8] T. Misawa and S. Kuninaga, "The first report of tomato foot rot caused by Rhizoctonia solani AG-3 PT and AG-2-Nt and its host range and molecular characterization," Journal of General Plant Pathology, vol. 76, no. 5, pp. 310-319, 2010.

[9] E. E. Kuramae, A. L. Buzeto, M. B. Ciampi, and N. L. Souza, "Identification of Rhizoctonia solani AG 1-IB in lettuce, AG 4 HG-I in tomato and melon, and AG 4 HG-III in broccoli and spinach, in Brazil," European Journal of Plant Pathology, vol. 109, no. 4, pp. 391-395, 2003.

[10] L. C. Van Loon, M. Rep, and C. M. J. Pieterse, "Significance of inducible defense-related proteins in infected plants," Annual Review of Phytopathology, vol. 44, pp. 135-162, 2006.

[11] N. Benhamou, M. H. A. J. Joosten, and P. J. G. M. De Wit, "Subcellular localization of chitinase and of its potential substrate in tomato root tissues infected by Fusarium oxysporum f. sp. Radicis-lycopersici," Plant Physiology, vol. 92, no. 4, pp. 1108-1120, 1990.

[12] N. Danhash, C. A. M. Wagemakers, J. A. L. van Kan, and P. J. G. M. de Wit, "Molecular characterization of four chitinase cDNAs obtained from Cladosporium fulvum-infected tomato," Plant Molecular Biology, vol. 22, no. 6, pp. 1017-1029, 1993.

[13] J. P. Wubben, C. B. Lawrence, and P. J. G. M. De Wit, "Differential induction of chitinase and 1,3- $\beta$-glucanase gene expression in tomato by Cladosporium fulvum and its racespecific elicitors," Physiological and Molecular Plant Pathology, vol. 48, no. 2, pp. 105-116, 1996.

[14] P. Taheri and S. Tarighi, "Cytomolecular aspects of rice sheath blight caused by Rhizoctonia solani," European Journal of Plant Pathology, vol. 129, no. 4, pp. 511-528, 2011.

[15] S. Lurie, E. Fallik, A. Handros, and R. Shapira, "The possible involvement of peroxidase in resistance to Botrytis cinerea in heat treated tomato fruit," Physiological and Molecular Plant Pathology, vol. 50, no. 3, pp. 141-149, 1997.

[16] C. M. Rick and J. I. Yoder, "Classical and molecular genetics of tomato: highlights and perspectives," Annual Review of Genetics, vol. 22, pp. 281-300, 1988.

[17] A. Yildiz and M. Timur Döken, "Anastomosis group determination of Rhizoctonia solani Kühn (Telemorph: Thanatephorus cucumeris) isolates from tomatoes grown in Aydin, Turkey and their disease reaction on various tomato cultivars," Journal of Phytopathology, vol. 150, no. 10, pp. 526-528, 2002.

[18] K. Schmidt, B. Heberle, J. Kurrasch, R. Nehls, and D. J. Stahl, "Suppression of phenylalanine ammonia lyase expression in sugar beet by the fungal pathogen Cercospora beticola is mediated at the core promoter of the gene," Plant Molecular Bio$\log y$, vol. 55, no. 6, pp. 835-852, 2004.

[19] M. A. Doster and R. M. Bostock, "Effects of low temperature on resistance of almond trees to Phytophthora pruning wound 
cankers in relation to lignin and suberin formation in wounded bark tissues," Phytopathology, vol. 78, no. 4, pp. 478-483, 1988.

[20] M. M. Campbell and B. E. Ellis, "Fungal elicitor-mediated responses in pine cell cultures-I. Induction of phenylpropanoid metabolism," Planta, vol. 186, no. 3, pp. 409-417, 1992.

[21] P. Taheri and S. Tarighi, "Riboflavin induces resistance in rice against Rhizoctonia solani via jasmonate-mediated priming of phenylpropanoid pathway," Journal of Plant Physiology, vol. 167, no. 3, pp. 201-208, 2010.

[22] S. Sareena, K. Poovannan, K. K. Kumar et al., "Biochemical responses in transgenic rice plants expressing a defence gene deployed against the sheath blight pathogen, Rhizoctonia solani," Current Science, vol. 91, no. 11, pp. 1529-1532, 2006.

[23] B. Mauch-Mani and A. J. Slusarenko, "Production of salicylic acid precursors is a major function of phenylalanine ammonia-lyase in the resistance of arabidopsis to Peronospora parasitica," Plant Cell, vol. 8, no. 2, pp. 203-212, 1996.

[24] P. Taheri and S. Tarighi, "A survey on basal resistance and riboflavin-induced defense responses of sugar beet against Rhizoctonia solani," Journal of Plant Physiology, vol. 168, no. 3, pp. 1114-1122, 2011.

[25] S. C. Chen, A. R. Liu, F. H. Wang, and G. J. Ahammed, "Combined overexpression of chitinase and defensin genesin transgenic tomato enhances resistance to Botrytis cinerea," African Journal of Biotechnology, vol. 8, no. 20, pp. 5182-5188, 2009.

[26] G. Sridevi, C. Parameswari, N. Sabapathi, V. Raghupathy, and K. Veluthambi, "Combined expression of chitinase and $\beta$ 1,3-glucanase genes in indica rice (Oryza sativa L.) enhances resistance against Rhizoctonia solani," Plant Science, vol. 175, no. 3, pp. 283-290, 2008. 

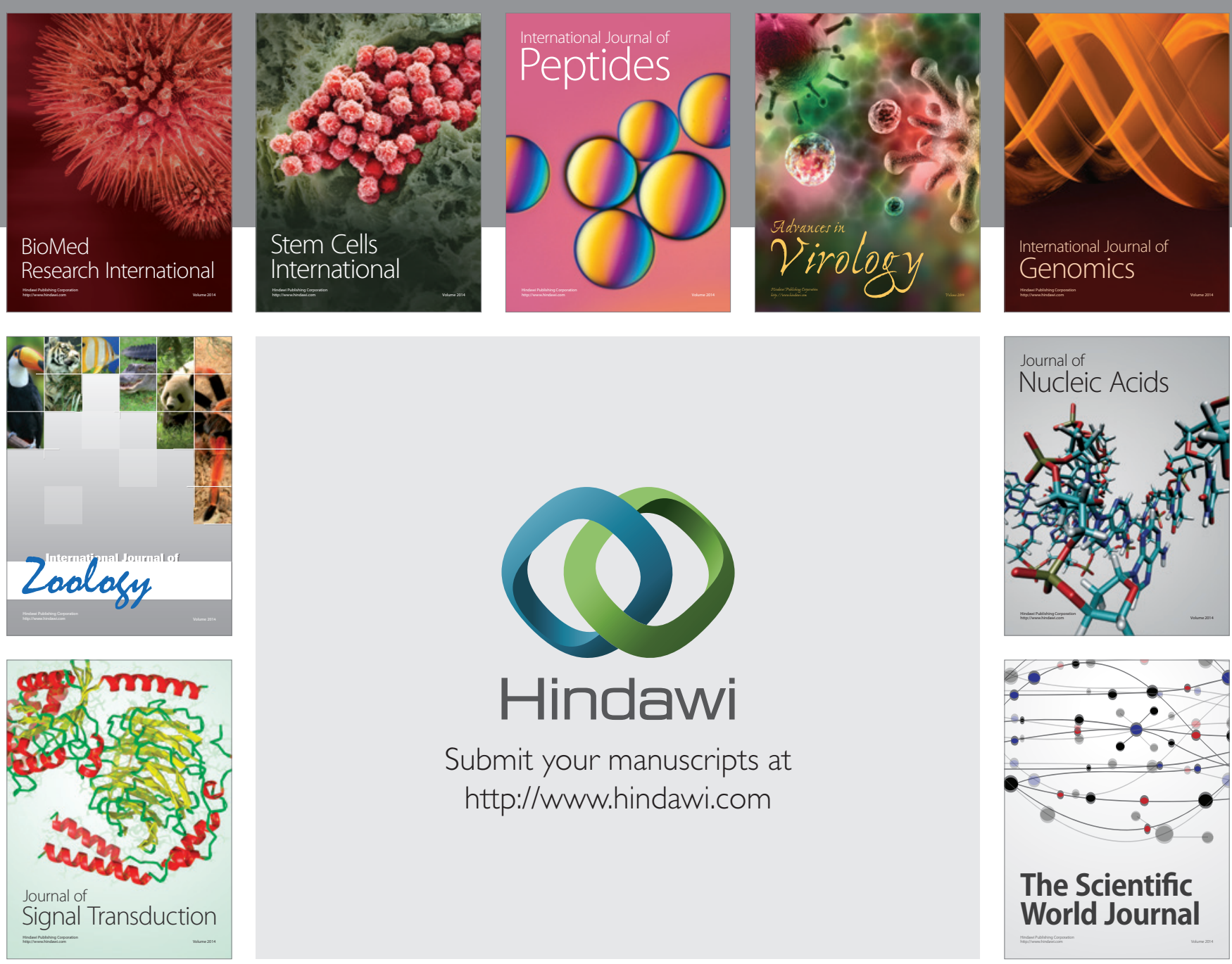

Submit your manuscripts at

http://www.hindawi.com
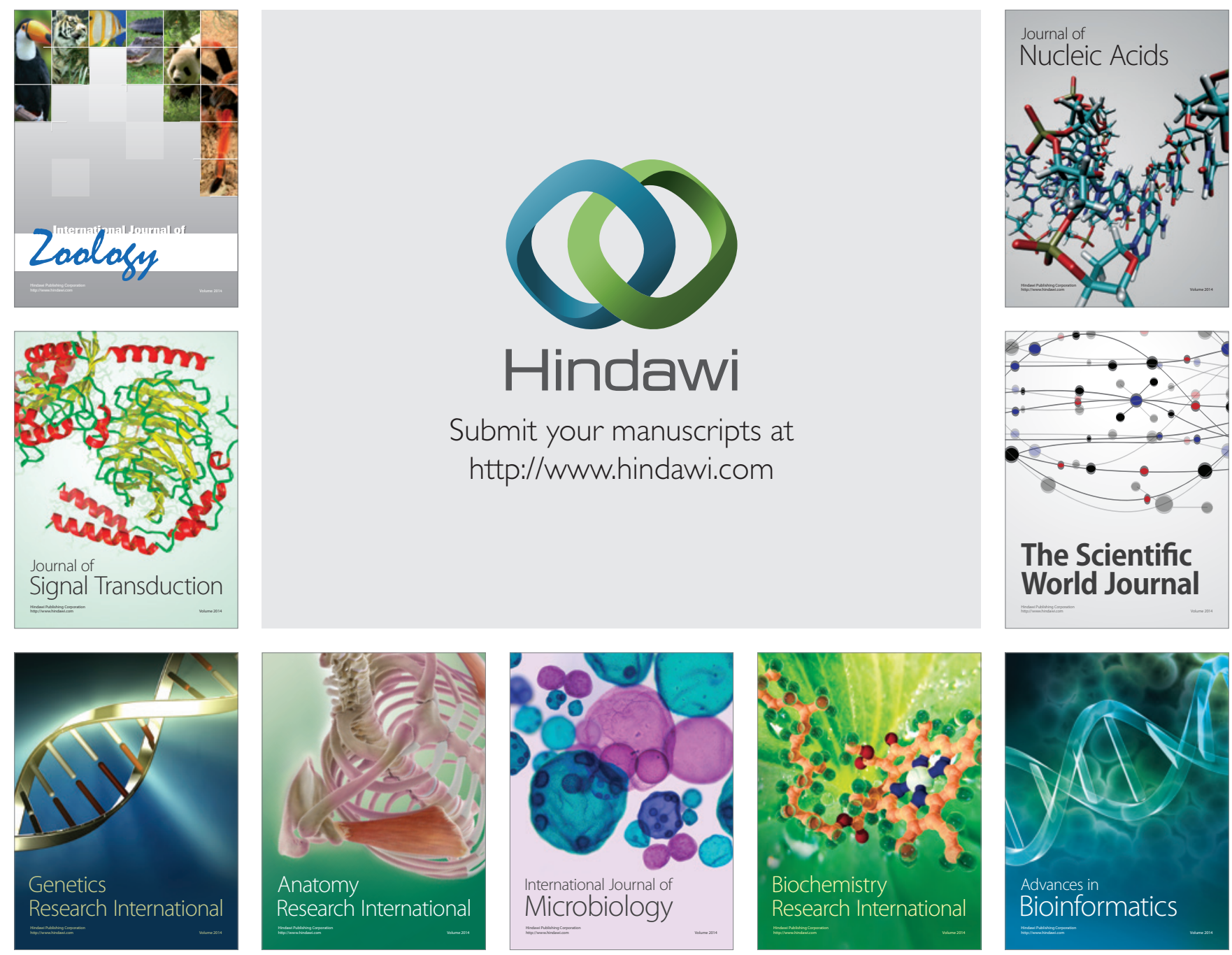

The Scientific World Journal
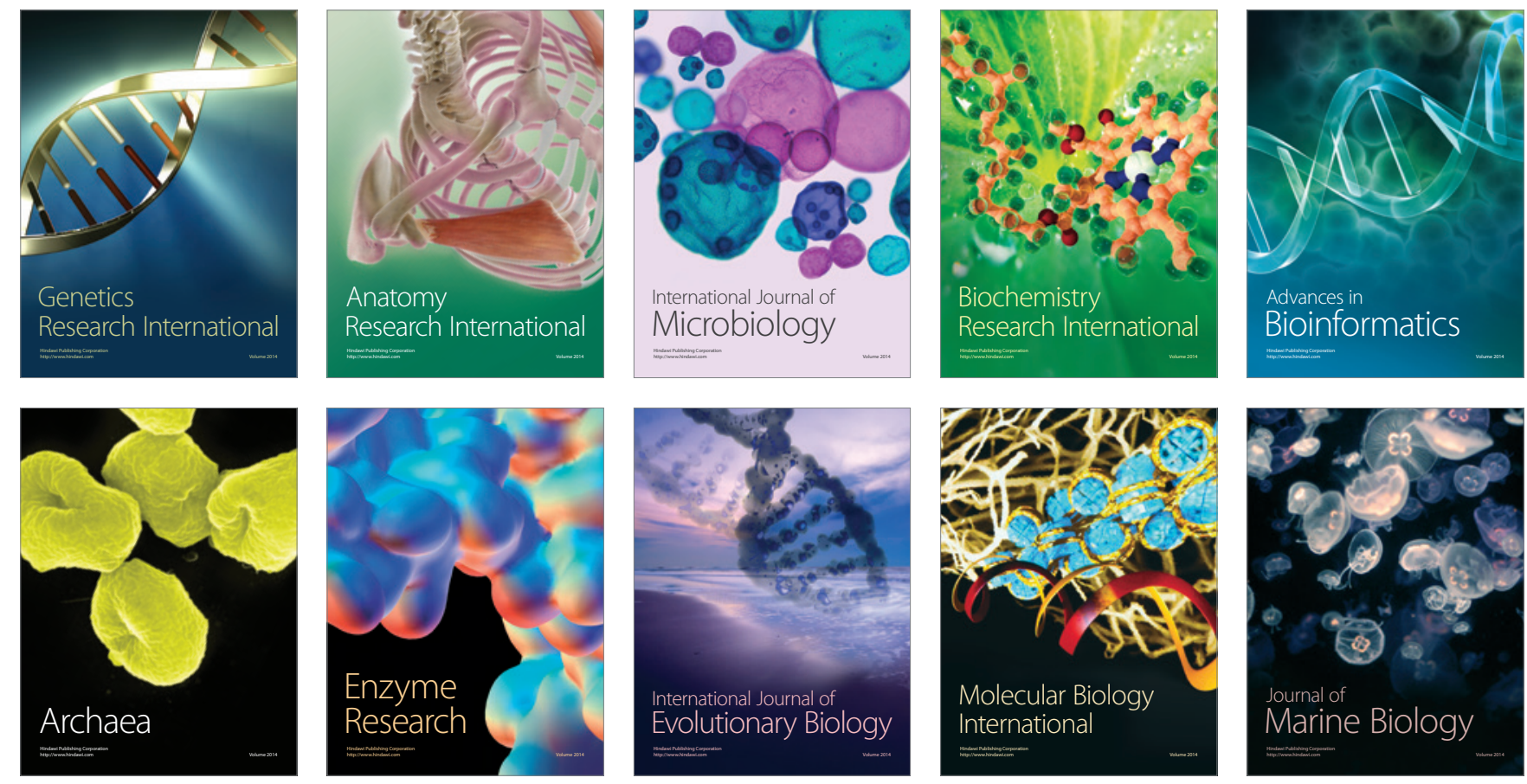